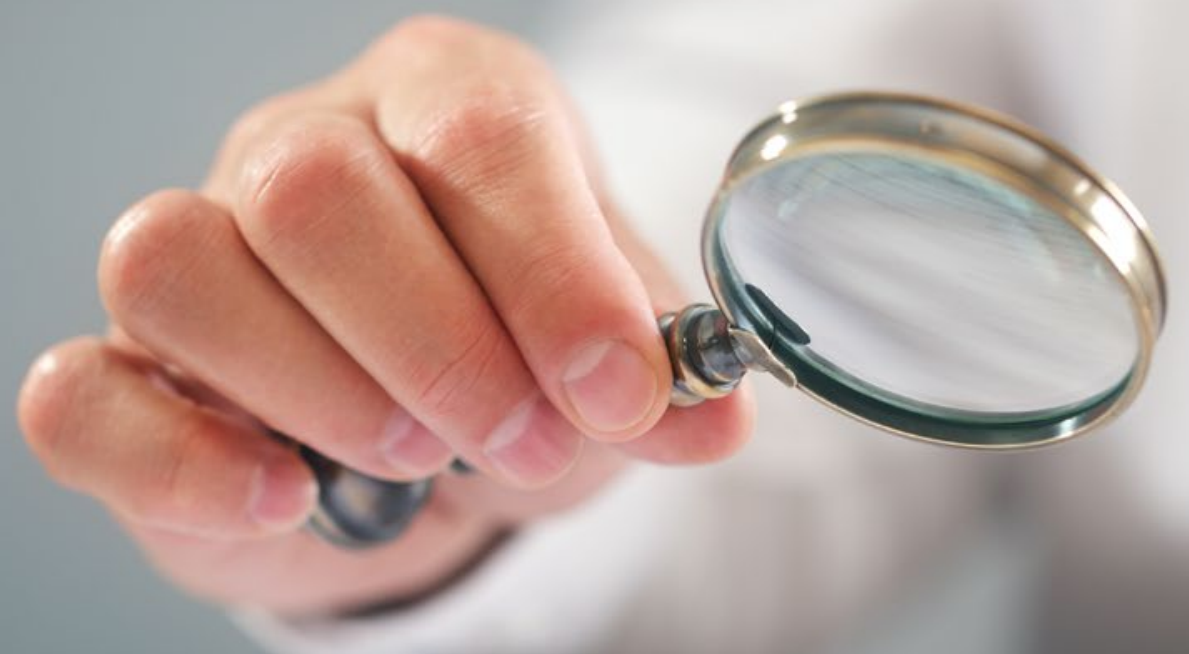

\title{
Wirtschaftlich denken?
}

Liebe Kolleginnen und Kollegen, jeder Zahnarzt, der eine Kassenzulassung hat, kennt sie. Keiner liebt sie. Niemand freut sich, wenn sie per Post angekündigt wird. Die Rede ist von der Wirtschaftlichkeitsprüfung. Stellen wir uns also die Frage: Warum gibt es sie überhaupt?

Die Antwort ist einfach und gleichzeitig unbefriedigend. Die Wirtschaftlichkeitsprüfung ist im Gesetz verankert. Gemäß $\$ 106$ SGB V sind Krankenkassen und Kassenzahnärztliche Vereinigung verpflichtet, gemeinsame Prüfgremien einzurichten. Diese Gremien werden zwar von den beiden letztgenannten Institutionen gemeinsam eingerichtet, sind aber selbstständig.

Deren Aufgabe ist es, die Abrechungen der Vertragszahnärzte daraufhin zu überprüfen, ob das Wirtschaftlichkeitsgebot nach $\$ 12$ SGB V beachtet wurde. Es geht also nicht darum, die Korrektheit der Abrechnung anzuzweifeln. Vielmehr soll festgestellt werden, ob die geprüften Praxen bei den behandelten Patienten ausreichend, zweckmäßig und wirtschaftlich gearbeitet haben und auch das Maß des Notwendigen nicht überschritten wurde.

\section{Nach dem Rasenmäher-Prinzip weggekürzt}

Da konkrete Einzelfallprüfungen für Leistungen, die teilweise Jahre zurückliegen, naturgemäß schwierig sind, greifen die Prüfgremien meistens auf statistische Auswertungen zurück. Mit deren Hilfe werden dann etwaige Überschreitungen von Durchschnittswerten häufig nach dem Prinzip „Rasenmäher" weggekürzt.

An dieser Stelle offenbaren sich die wahren Absichten des Gesetzgebers. Es handelt sich um ein Instrument, das Abrechnungsverhalten zu steuern und Kosten zu senken. Besonders ärgerlich ist in diesem Kontext das permanente Begehren der Krankenkassen, Rückflüsse aus der Wirtschaftlichkeitsprüfung auch dann für sich zu vereinnahmen, wenn die Gesamtvergütungsobergrenze überschritten wird. Individualität und Qualität spielen in diesem Kontext keine Rolle.

Kommen wir zur Diagnose. Die Wirtschaftlichkeitsprüfung ist bei Licht betrachtet nichts anderes als das Symptom einer Krankheit, die Sachleistungsprinzip genannt wird.

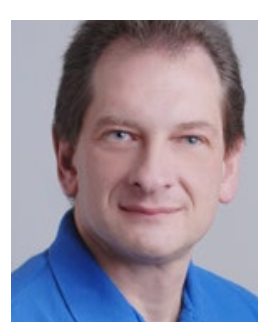

\section{Dr. Reiner Zajitschek}

Mitglied des FVDZ Bundesvorstandes

„Sachleistung ist diskriminierend“, verkündete schon vor Jahren Renate Künast (B 90/Die Grünen), und so sehen es viele Umverteilungsfetischisten immer noch. Warum also soll für den Sozialhilfeempfänger (der hier gemeint war) etwas anderes gelten als für das Mitglied der GKV, das immerhin Beiträge zahlt?

\section{Mehr Direktabrechnung mit Kostenerstattung}

„Wirtschaftlich denken“ heißt, dass man Geld sinnvoll und sparsam einsetzt. „Wirtschaftlich handeln“ heißt für die Zahnarztpraxis, dass Aufwand und Ertrag in einem vernünftigen Verhältnis stehen müssen. Der Gesetzgeber will es so, dass den GKV-Mitgliedern nur ein eingeschränktes Leistungsspektrum als Sachleistung gewährt wird - wir können aber auch anders.

Packen wir also das Übel an der Wurzel und kämpfen wir bei jeder Gelegenheit um mehr Direktabrechnung mit Kostenerstattung und somit mehr Transparenz und Individualität. Dafür müssen wir uns täglich selbst in unserer Praxis einsetzen, indem wir bestehende Möglichkeiten nutzen und das Patientengespräch suchen. Darüber hinaus benötigen wir zusätzliche Freiräume dafür kämpft Ihr Freier Verband Deutscher Zahnärzte.

Mit den besten kollegialen Grüßen,

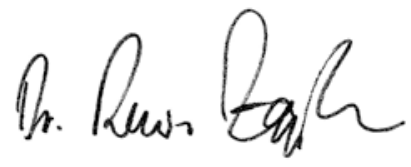

